\title{
Sustainable Urban Facilities Design Based on Emotional Narratives
}

\author{
Wenkai Xue ${ }^{1}$, Xiuli Ge ${ }^{2,3}$, Yan Zhao ${ }^{{ }^{*}}$ \\ ${ }^{1}$ College of Industrial Design, Luxun Academy of Fine Arts, Shenyang, Liaoning, China \\ ${ }^{2}$ Faculty of Engineering and Technology, Liverpool John Moores University, Liverpool, UK \\ ${ }^{3}$ Southampton International College, Dalian Polytechnic University, Dalian, Liaoning, China
}

*Corresponding Author.

\begin{abstract}
Emotional narration can provide innovative ideas for sustainable urban facilities. The design of sustainable urban facilities starts from the concept of emotional design, focuses on improving the user's experience, implements innovative design process, extends the product life cycle, utilizes new sustainable materials, combines emotional factors with product functions, and gets more citizens participate in the design process. The research result shows that the gradual emotional narration thinking change from a single dimension to multiple dimensions can promote the design innovation, upgrades service of urban public facilities, and enhances the connection between users and urban facilities. It can be seen that a series of sustainable urban facilities designed based on emotional narration can serve as effective carriers for communication between urban residents and the city. Sustainable urban facilities with humanistic care are dedicated to making urban residents realize they cannot only enjoy the urban facilities, but also participate in the creation of better social environment.
\end{abstract}

Keywords: emotional design, narrative design, sustainable design, urban public facilities

\section{Introduction}

In August 1966, a series of papers on narration were published in the magazine Communication, which marked the beginning of narratology ${ }^{[1]}$. In 1969, French scholar Tzvetan Todorov formally put forward the theory of Narratology. Since then, narratological study has gradually developed and been employed in interdisciplinary research. Emotional design belongs to the narrative design thinking. As a leading design thinking method, emotional narrative plays an important role in the design process ${ }^{[2]}$. Zhong Rong, a Chinese literary critic who lived in the period of the Southern Dynasties believed that poetry creation should be based on narration and emotions. Motoori Norinaga, a great Japanese scholar in the Edo period, pointed out the concept of "sorrow for objects" and advocated the artistic creation with true feelings ${ }^{[3]}$. The narration in design is that the designer (narrator) conveys the intention to the consumer (receiver) through the narrative story (media), thus evoking the consumer's inner feelings, memories and associations ${ }^{[4]}$. To sum up, emotional narrative design is a method of narrating and presenting stories to realize the communication and exchange of information between people and products and achieve better emotional or cultural experience.

Before the concrete analysis of the design process, it is necessary to clarify the following two questions. First, why does emotional narrative pay more and more attention in design? Emotions and narratives help to establish a Universal Link between products and consumers (users) ${ }^{[5]}$. This link has multiple dimensions. For example, a cup can remind a customer of his childhood memory. This emotion will play an important role when the customer makes decisions in buying products and this makes the cup a carrier of the consumer's memory. This situation is very common in cultural and creative products. Fig 1 breaks down the reasons why consumers of different ages buy cultural and creative products. It is found that as the age of users increases, the degree of recognition of emotional factors in cultural and creative products continues to rise.

ISSN: 0010-8189

(C) CONVERTER 2021

www.converter-magazine.info 


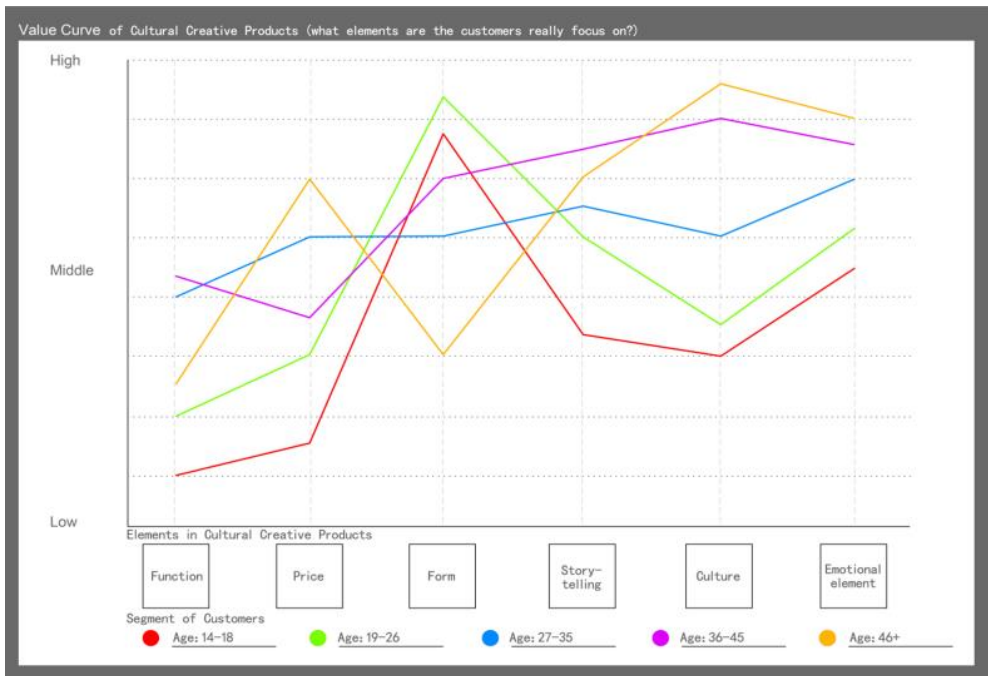

Fig 1: Customer evaluation of the attributes of purchasing cultural and creative products

In addition, will the design that focuses on the functions of the products disappear in the market? Facing the future market, practicality is still one of the decisive factors of product design. At the same time, product functions can also include emotional functions. As shown in Fig 2, for the comparison of design factors of different juicers, products with strong emotional narrative functions are beneficial to increase the added value of the products. This not only prolongs the service life of the product, but also effectively increases the sales of the product.

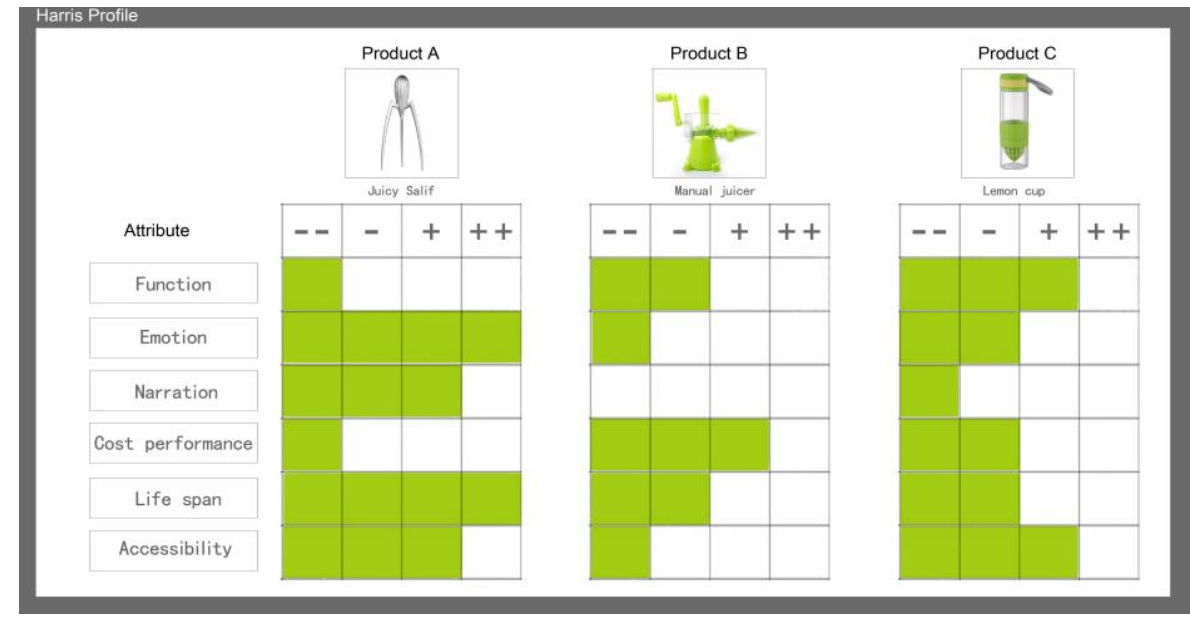

Fig 2: The Factor analysis of different types of juicer

\section{Sustainable Urban Facility Design Trends}

To conceive the development trend of future cities from the perspective of designers, this often gives designers and city managers more say in urban planning. However, will the idea of perfecting the city be understood and recognized by urban residents? This brings up an important issue again. How will urban facilities better serve people in the future? As shown in Fig 3, future urban exploration is divided into three stages by using the method of detecting weak signals. Among them, 1-3 years is the current design stage. 3-5 years is the near-future design stage and 5-20 years is the future design stage ${ }^{[6]}$. Based on the classification and analysis of events that may trigger future changes in urban development, the following questions are summarized. First, how can urban waste be used more effectively? Second, how will the remaining resources of the city be used more effectively? Third, how will urban facilities strengthen the relationship between people? Fourth, will AI play a decisive role in future

ISSN: 0010-8189

C) CONVERTER 2021

www.converter-magazine.info 
urban development? Fifth, how can the health of urban residents be monitored? These problems can provide more ideas for the design of urban facilities. However, the simple solution of these problems will not necessarily promote the prosperity of the city. Designers can raise citizens' awareness of protecting the cities through emotional narrative thinking, and then serve urban residents more effectively.

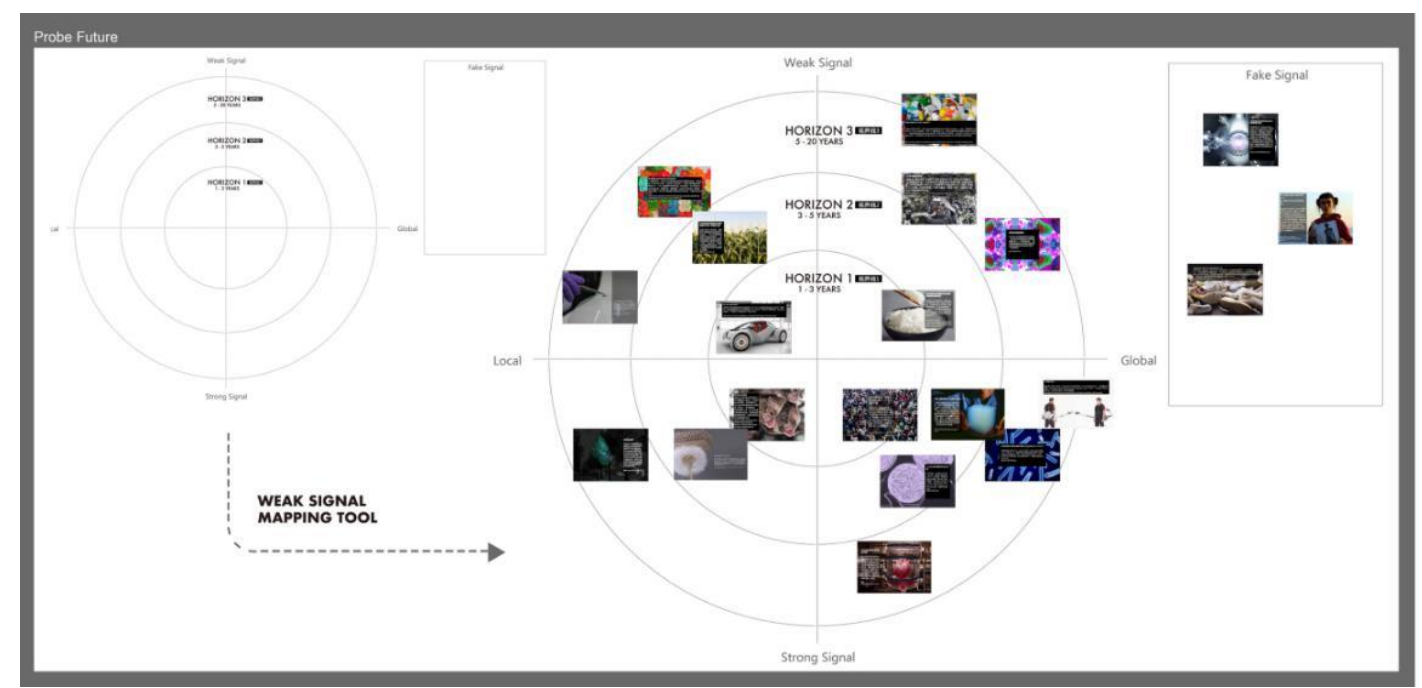

Fig 3: Exploration of future sustainable urban development

\section{Design Methods of Sustainable Urban Facilities}

\subsection{Combined brainstorming}

The combined brainstorming method uses the combination design method of brainstorming and it can be used as an innovative way to design sustainable urban facilities. The combined brainstorming is an innovative method based on two or more things, following a certain principle and using effective ways of combination ${ }^{[7]}$. The characteristic of this method is to take combination as the center, organically combine the seemingly unrelated things, and combine many elements into one, thus producing unexpected, wonderful and novel innovative results ${ }^{[8]}$. When looking for ideas for design topics, designers usually use brainstorming as the main way to produce as many design elements of sustainable cities as possible, classify these elements, and then list the elements on the $\mathrm{X}$ and $\mathrm{Y}$ axes and compare them (see Fig 4). By doing so, designers can also get valuable and potential creative ideas. In the creative stage of design, these innovative topics, different combination modes such as the combination of purposes, emotions and functions can produce original design works more effectively ${ }^{[9]}$.
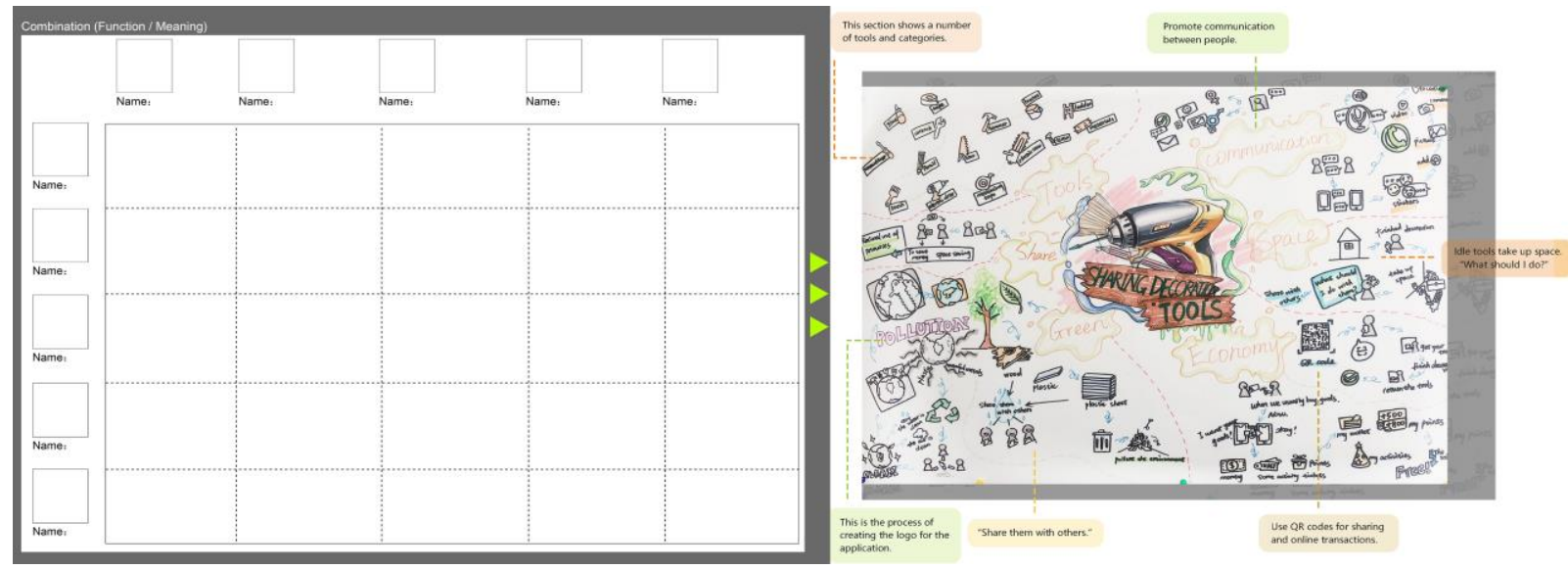

Fig 4: Template and a design case using combined brainstorming method

ISSN: 0010-8189

(C) CONVERTER 2021

www.converter-magazine.info 


\subsection{Functional design --- the first layer of design thinking}

Innovation can be understood as a creative way for users to provide better problem-solving methods with traditional design ideas ${ }^{[10]}$. This leads to the innovation from a functional perspective, which is the first level of creative thinking. The principle "form follows function" takes product function as the basis of product existence. If different functions are integrated and superimposed in a product, many new ideas will come out. This creative derivation method of combined design is not only simple and straightforward, but also more valuable in providing an effective way for making new products. For example, an ecological street light system can use the electric energy generated by green plants in the park ${ }^{[11]}$. Designers have found that this rational combination method can solve the problems of product innovation. The more irrelevant things are added together, the more creative the new products will be. Does design innovation include other factors? This will lead to the second level of design ideas (see Fig 5).

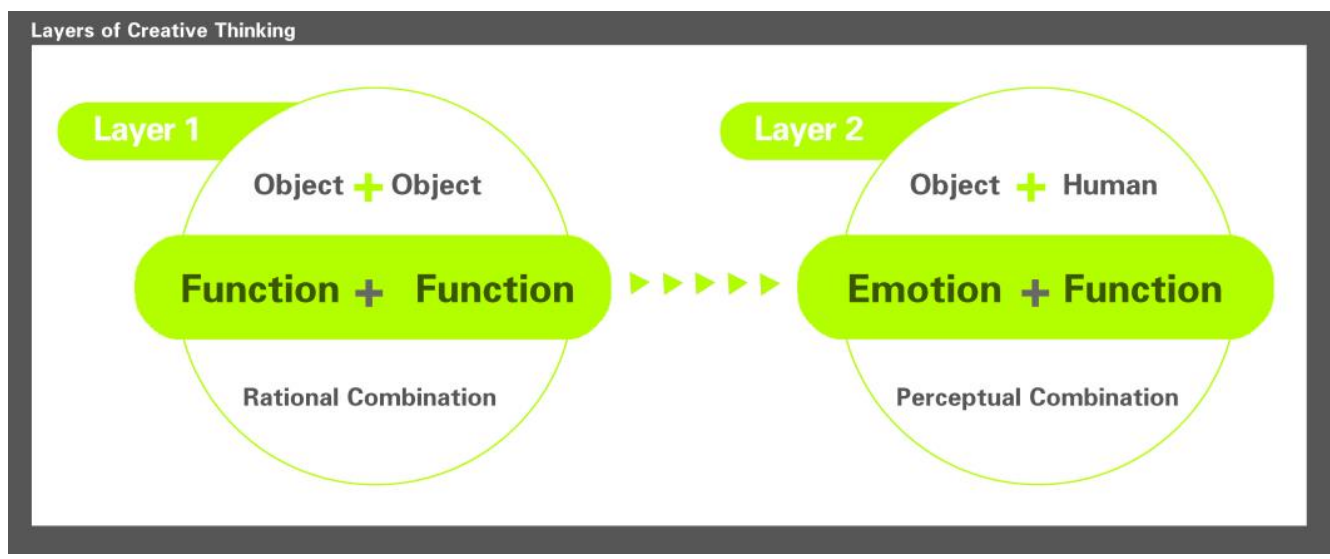

Fig 5: Layers of creative thinking

3.3 Emotional narrative design --- the second layer of design thinking-

Emotional design is a method of regulating design through emotion and behavior, while narrative design is presented in the design in a narrative and perceptual way ${ }^{[12]}$. Its content and information will be transformed into deeply rooted stories in an intuitive, reflective or relaxed way, and then accepted by users and internalized in their mind ${ }^{[13]}$. Compared with the first kind of rational combination of objects or functions, the second level of creative thinking can be achieved when creativity involves the influence of design on the user's psychology. When users' physical needs for products are met, products that can interact with users psychologically will be more popular. Therefore, emotional narrative design attempts to transfer human feelings into products. This will be one of the main research issues of future design. Then, based on the practical function of products, some human emotions such as expectation, joy, sadness, humor, and irony are projected appropriately, which will increase the narrative and entertaining features of the products. Fig 6 specifically analyzes how the designer integrates emotional narration into the design and passes it to consumers effectively.

ISSN: 0010-8189 


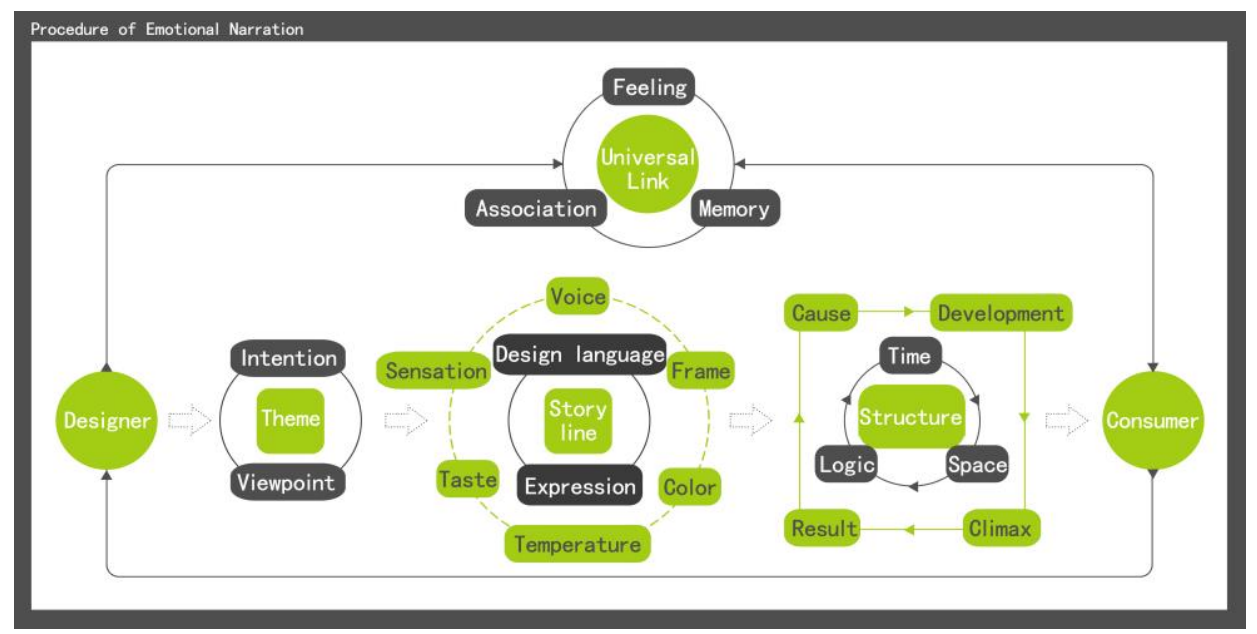

Fig 6: Procedure of emotional narration

\section{Shared Facilities in Sustainable Urban Communities}

A sustainable city refers to a city that can provide its residents with sustainable welfare under certain social and economic conditions and on the premise that the urban ecosystem services are not reduced. One of the basic criteria of a sustainable city is to encourage individuals to take their ecological responsibility ${ }^{[14]}$. Some problems such as resource waste also arise with the urbanization ${ }^{[15]}$. For example, it has been a common problem for urban residents to deal with a large number of decoration tools after their home decoration. EX-change community tool sharing facilities is established to help solve the problem. As shown in Fig 7, EX-change encourages residents living in the same community to share the unused decorations tools with others. By doing so, the interaction among community residents can also be improved through the activity of sharing things with others.
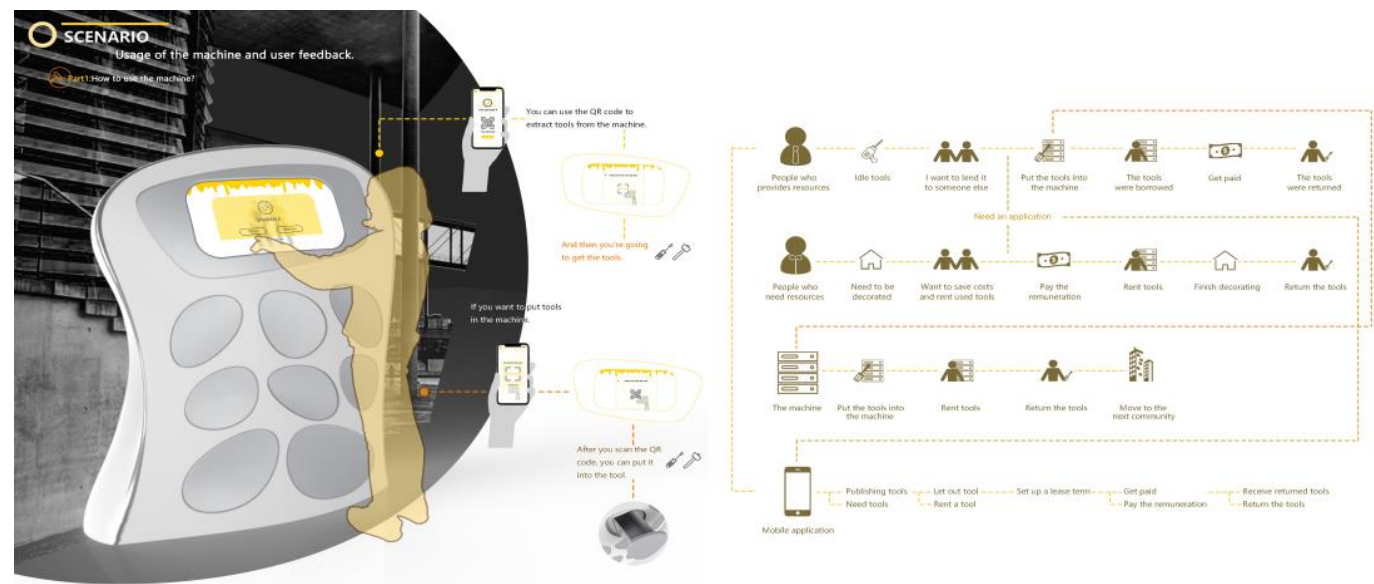

Fig 7: Design case of EX-change community tool sharing facility

In terms of emotional narration, EX-change tries to increase the connection between users of shared tools through services and experience, encouraging residents to participate in community unused tool sharing activities from the perspectives of building environment-friendly cities and communities, realizing personal values, and improving neighborhood harmony. More residents are welcome to participate in this activity to experience the happiness of sharing.

\section{Narrowing the Distance between the City and Its Residents with Emotional Narration}

In order to make the design more entertaining and arouse more people's attention, Storytelling can create a ISSN: 0010-8189

(C) CONVERTER 2021

Www.converter-magazine.info 
background atmosphere ${ }^{[16]}$. As shown in Fig 8, this design focuses on the problem of existence of urban stray animals. The life cycle of the stray animals is usually no more than 2 years in many cities with cold wintertime. In order to make more people notice this problem, Fig 8 records the life of stray dogs through doing background research and on-site shooting. The poor living conditions of stray animals are truly displayed to arouse people's attention and sympathy. This study starts with narration, sorts out and displays the design definition, target users, real scenarios, and moves on to the design practice.
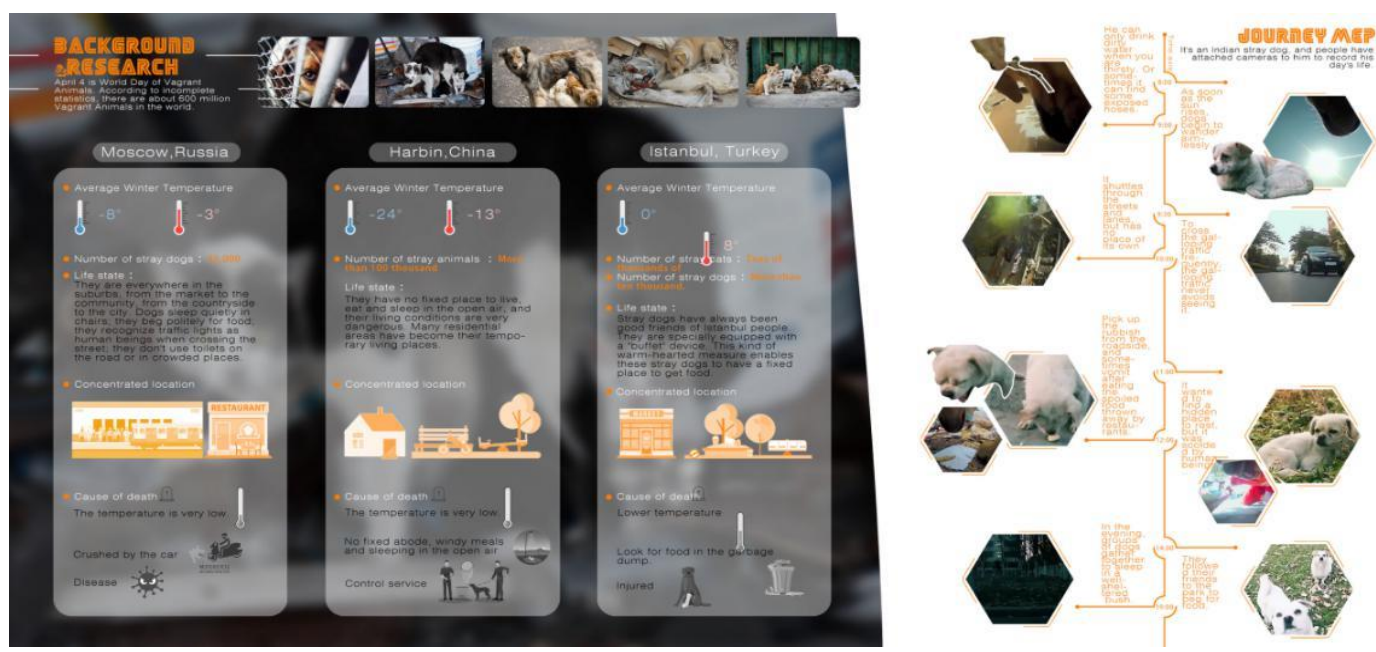

Fig 8: Investigation on the living conditions of stray animals in cold cities

At the beginning of the design, the biggest challenge is to arouse more people's enthusiasm for helping stray animals. Then the integration of urban facilities with stray animals and urban residents requires the use of some new factors. For example, the burning of domestic waste can generate heat and the heat can be stored in the facility to help the stray animals survive in the cold wintertime. This kind of design can deal with the garbage in the cities and alleviates the survival problem of stray animals in winter. Another important impact of this design is that it can encourage more urban residents to participate in this activity. A sustainable circle is formed through building the link between the main elements within the design.

Fig 9 shows the service facility of Harbor city, which uses emotional narration to create a better service experience for users of the facility. First, Harbor inputs the concepts of waste incineration and stray animal rescue to users at the same time, which will help users to intuitively experience the value of their actions after putting garbage in it and encourage more urban residents to participate in it. Second, in terms of energy utilization, Harbor can maintain a basic recycling circle. The electric energy generated by wind energy is used for garbage incineration and the heat energy generated by garbage incineration is used for stray animals to stay warm. Third, from the perspective of caring for stray animals, Harbor encourages urban residents to separate dry and wet garbage for garbage incineration. Considering the above aspects, the design of sustainable urban facilities such as Harbor uses emotional narration to narrow the distance between the city and its residents.

ISSN: 0010-8189 


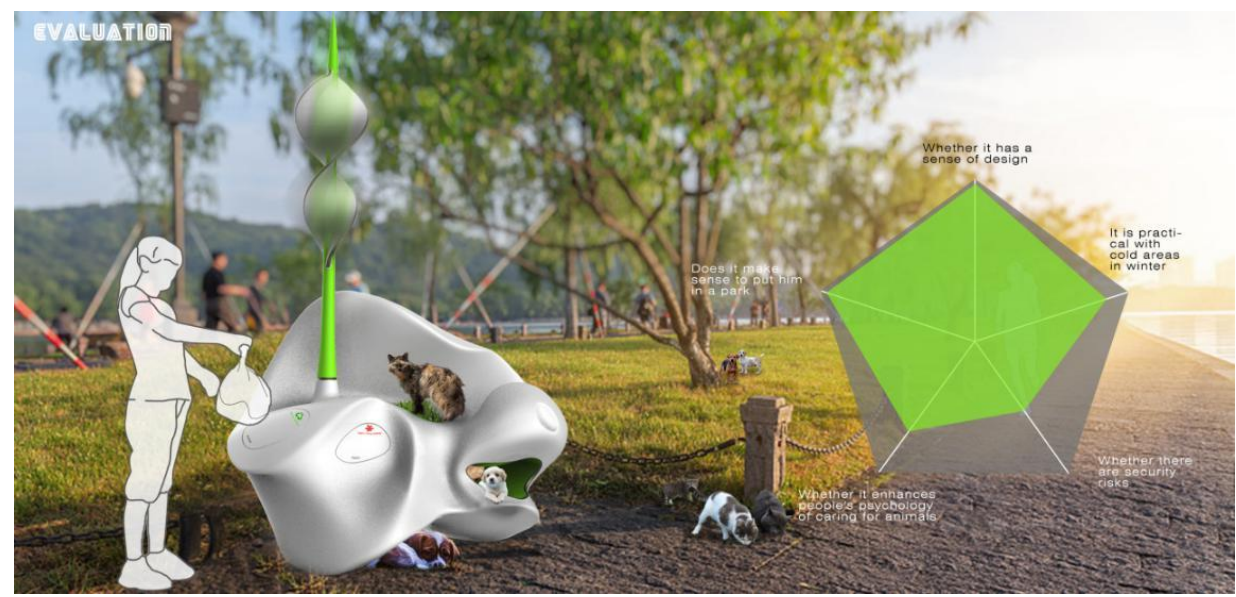

Fig 9: Design case of Harbor urban waste incineration and stray animal temporary living facilities

\section{Conclusion}

From the perspective of resources, the sustainable development of a city is a process in which a city continues to pursue its inherent natural potential and its purpose is to build a green city based on survival capacity. Sustainable urban development should pursue a city in which human interaction, information dissemination, and culture have been greatly developed in the social aspect, marked by vigor, stability, and equity. The future scenario of a sustainable city will include functional, emotional, humanistic, economic and other dimensions of sustainable development. From the perspective of emotional narration, it will stimulate the creative enthusiasm of urban residents and allow residents and city managers to participate in the development and construction of the city, which will become a more effective plan and solution for sustainable cities.

\section{Acknowledgements}

This article is sponsored by the research project of Luxun Academy of Fine Arts (2018): Research on the Innovative Design of Public Facilities Based on Renewable Energy (Project No.: 20181m121).

\section{References}

[1] Y. Zhuang, "Research on 'detour' narrative design in trauma exhibition,” Journal of Nanjing Institute of Art (Art and Design), vol. 2, no. 02, pp. 95-102, 2019.

[2] L.D. Liang, J. Shen, "Narrative interaction design strategy under intergenerational communication," Packaging engineering, vol. 10, no. 20, pp.181-186, 2019.

[3] K. Zhang, Z.Y. Gao, "Research on children's medical product design based on narrative design," Decoration, vol. 1, no. 01, pp. 111-113, 2018.

[4] T.Y. Geng, X.T. Rui, M. Jiang, "Exploration of interesting product design based on narrative," Packaging Engineering, vol. 6, no. 12, pp. 168-174, 2019.

[5] H.Y. Wang. "Research on narrative design of cultural and creative products based on experience level," Packaging Engineering, vol. 8, no.16, pp. 330-335, 2020.

[6] K. X. Wang, "Narrative design of historical monuments: a case study of Nanjing Victory Monument crossing the Yangtze River,” Decoration, vol. 2, no. 2, pp. 128-129, 2020.

[7] L. J. He, "Research on conceptual product design strategy based on narrative design," Journal of Kashgar University, vol. 2, no. 4, pp. 76-81, 2020.

[8] Q. Zhang, "Semiotic interpretation of narrative design," Journal of Nanjing Institute of Art (Fine arts and Design), vol. 4, no. 4, pp. 127-131, 2020.

[9] Z.L. Luan, D.Q. Shi, "Multidimensional non-linear narrative: experiential narrative design in the new ISSN: 0010-8189 
media era," Decoration, vol. 4, no. 4, pp. 30-33, 2017.

[10] S. Zhang, "Hierarchical research on emotional expression of narrative space: a case study of Melbourne War Memorial Hall,” Art Work, vol. 2, no. 2, pp. 97-99, 2020.

[11] J. Li, "Duty, narration and purity: Zhang Jian's ideal of industrial design," Decoration, vol. 12, no. 12, pp. 52-57, 2016.

[12] Y, Di, "Image construction and communication in visual narrative," Decoration, vol. 2, no. 2, pp. 130$131,2015$.

[13] S. Li, H. Feng, “Application of availability in product design,” Packaging engineering, vol. 3, no. 6, pp. 228-231, 2020.

[14] Y, Gu, E. H. Zhai, “Application of interactive information transmission in display design,” Art Work, vol. 6, no. 6, pp. 99-101, 2019.

[15] J.L. Wu, “Application of emotional design in food packaging," Packaging Engineering, vol. 1, no. 2, pp. 284-286, 2020.

[16] M. Ding, Y. Cheng, X.G. Huang, "Research status and progress of Kansei engineering design method," Mechanical Design, vol. 1, no. 1, pp. 121-127, 2020. 